\title{
A METHOD FOR EVALUATION OF SUSPENSION QUALITY EASY APPLICABLE TO PRACTICE: THE EFFECT OF MIXING ON FLOC PROPERTIES
}

\author{
PETRA BUBAKOVA, MARTIN PIVOKONSKY, LENKA PIVOKONSKA
}

Institute of Hydrodynamics, Academy of Sciences of the Czech Republic, v.v.i., Pod Patankou 5, 16612 Prague 6, Czech Republic; Mailto: bubakova@ih.cas.cz

\begin{abstract}
The paper introduces the test of aggregation as a simple, inexpensive method of evaluating suspension quality during drinking water treatment, suitable for use in both laboratory and operation conditions. The procedure and derivation of the aggregation test is described. The method is used for a demonstration of the influence of mean velocity gradient and mixing time on floc properties formed during the aggregation in a Couette reactor. It was proved that with increasing velocity gradient, the size of the aggregates present in the suspension decreases, and the suspension is substantially more homogeneous than with use of lower gradients. Further, it was confirmed that the size of aggregates reaches the steady state after a specific mixing time, which becomes shorter with increasing value of velocity gradient.
\end{abstract}

KEY WORDS: Aggregation, Drinking Water Treatment, Floc Properties, Flocculation, Test of Aggregation.

Petra Bubáková, Martin Pivokonský, Lenka Pivokonská: METODA HODNOCENÍ KVALITY SUSPENZE SNADNO POUŽITELNÁ V PRAXI: VLIV MÍCHÁNÍ NA VLASTNOSTI VLOČEK. J. Hydrol. Hydromech., 59, 2011, 3; 22 lit. 11 obr. 8 tab.

Příspěvek představuje test agregace jako jednoduchou a levnou metodu stanovení kvality suspenze při úpravě vody vhodnou pro použití v laboratorních i provozních podmínkách. Je popsán metodický postup i odvození testu agregace. Metoda je použita pro hodnocení vlivu stř̌edního gradientu rychlosti a doby míchání na vlastnosti vytvářených agregátů (vloček) při agregaci v Couettově reaktoru. Bylo prokázáno, že se vzrůstajícím gradientem se snižuje velikost agregátů přítomných v suspenzi a suspenze je značně více homogenní než při použití nízkých gradientů rychlosti. Dále bylo potvrzeno, že velikost agregátů dosahuje po určité době míchání stabilní hodnoty. Čas pro dosažení tohoto ustáleného stavu se zkracuje s rostoucí hodnotou použitého gradientu.

KLÍČOVÁ SLOVA: agregace, flokulace, test agregace, úprava pitné vody, vlastnosti agregátů.

\section{Introduction}

In drinking water treatment, a process of coagulation/aggregation/flocculation is widely used. Its purpose is to prepare a floc suspension suitable for the following separation step(s). The floc properties are influenced by chemical (dosage of coagulant, pH and alkalinity) (Annadurai et al., 2004; Polasek and Mutl, 2005) and physical (mixing conditions, i.e. mean velocity gradient and its distribution and the retention time) factors (Bouyer et al., 2005; Mutl et al., 2006).

In waterworks operation, the chemical factors, mainly the optimal dosage of coagulant, are commonly determined by jar tests. But the mixing conditions are usually not optimized. Nevertheless, these very physical conditions influence the properties of floc suspension (floc size, shape and density) and thus its separability. It is needed to point out that not every floc suspension is optimally separable by all available separation technologies. For instance, large, dense and strong flocs are ideal for double-stage separation by sedimentation and subsequent depth filtration. But if the direct depth filtration (single stage separation) is used for this very suspension, mentioned flocs form on the surface of the filtration media their own undesirable filtration layer, which leads to change of the depth sand filtration to surface filtration (Hereit et al., 1980). It follows from the given example that we need to know the suspension quality to choose the best separation technology, or on the contrary, to opti- 
mize mixing conditions to get a suspension suitable for existing technology.

The main properties characterizing the flocs are size and density. Since flocs have an irregular shape and they are porous an idealization is needed. The usual way is expressing the floc size by an equivalent diameter. But this method does not consider the floc permeability. That's why a fractal approach has been recently used. A fractal dimension that relates the floc mass $(M)$ with the size $(R)$ is expressed by the relation $M \propto R^{D_{F}}$, where $D_{F}$ is the mass fractal dimension, which can vary between 1 and 3 in 3-dimensional space (Gorczyca and Ganczarczyk, 1999; Gregory, 2009; Li et al., 2006). This tells us about the floc density; the higher the fractal dimension, the denser the floc; the lower the fractal dimension, the more open, highly branched and loosely bound floc structure (Chakraborti et al.; 2007, $L i$ et al., 2006).

There are a few studies which deal with the effect of mixing conditions (velocity gradient (or shear) and time of its action) on the resulting suspension quality in drinking water treatment (Bouyer et al., 2005; Hopkins and Ducoste, 2003; Li et al., 2006; Mutl et al., 2006). But they examine the floc properties in the terms of the basic research without relation to the following separation technologies.

There are plenty of methods for floc size determination. Gregory has summarized them in his review (2009). These methods are based on measuring of transmitted light-turbidity (Cheng et al., 2008) or scattered light ( $L i$ et al., 2006), they use microscopy, image analysis (Chakraborti et al., 2007; Kilander et al., 2006), or they estimate the floc properties from sedimentation analysis (Droppo et al., 2006; Fargues and Turchiuli, 2003; Tambo and Watanabe, 1979). They are able to provide very good image of size, shape and density of flocs present in the sample. But a problem can arise when transferring the floc suspension into the measurement device. The quality of suspension can change due to different shear conditions or when a dilution is needed. Moreover, the methods are often complicated to perform and the used devices are rather expensive. And there is one disadvantage which these methods have in common; they are not suitable for the use in waterworks operation.

However, there is a method called test of aggregation developed by Hereit et al. (1980) which is ideal for waterworks usage. It is simple, cheap and does not require any special instruments. It is based on settling properties of the flocs, and it sorts the flocs according to their suitability for following separation technologies. The method will be described in the next section in detail.

The aim of our paper is to show that test of aggregation can provide reliable results comparable with other authors' results, i.e. prove that with increasing velocity gradient (shear), the floc size decreases and the fractal dimension increases, which means that with higher $\bar{G}$, the flocs are smaller but more compact (or denser) and stronger (Bouyer et al., 2005; Hopkins and Ducoste, 2003; Li et al., 2006; Mutl et al., 2006). The method was used in the laboratory conditions. The Couette reactor was chosen as a mixing device for the uniformity of velocity gradient distribution (whose evaluation is not the subject of this paper) (Pivokonsky et al., 2003). The use of this method in pilot plant tests and in waterworks operation is reported in Pivokonsky et al. 2008, 2009.

\section{Methods}

\subsection{Test of aggregation - evaluation of suspension quality}

Hereit et al. (1980) developed a method, the test of aggregation, which sorts the flocs (aggregates) into four groups on the basis of their properties changing during their formation and the requirements of individual separation procedures (Tab. 1). The groups are: macro-aggregates (MA), microaggregates $(M I)$, primary aggregates $(P R)$ and nonaggregated particles (NA). A criterion for the categorization is the sedimentation velocity of the formed flocs. As it is evident, the method does not provide information about the exact size, shape and density of individual flocs, but rather give the general knowledge of suspension quality as a whole and help to adjust the operation conditions to reach the highest separation efficiency.

\subsubsection{Procedure}

After dosing the destabilization reagent and mixing under defined conditions (i.e. at waterworks before the inlet of formed suspension to the first or single separation stage), a sample is taken (in the laboratory conditions, it is possible to perform the aggregation test directly in the mixing vessel). The sampling vessel can be a usual 21 beaker or a jar used in jar tests. The suspension is allowed to settle directly in the sampling vessel, and a concentration of the basic metal constituent of the destabilization 


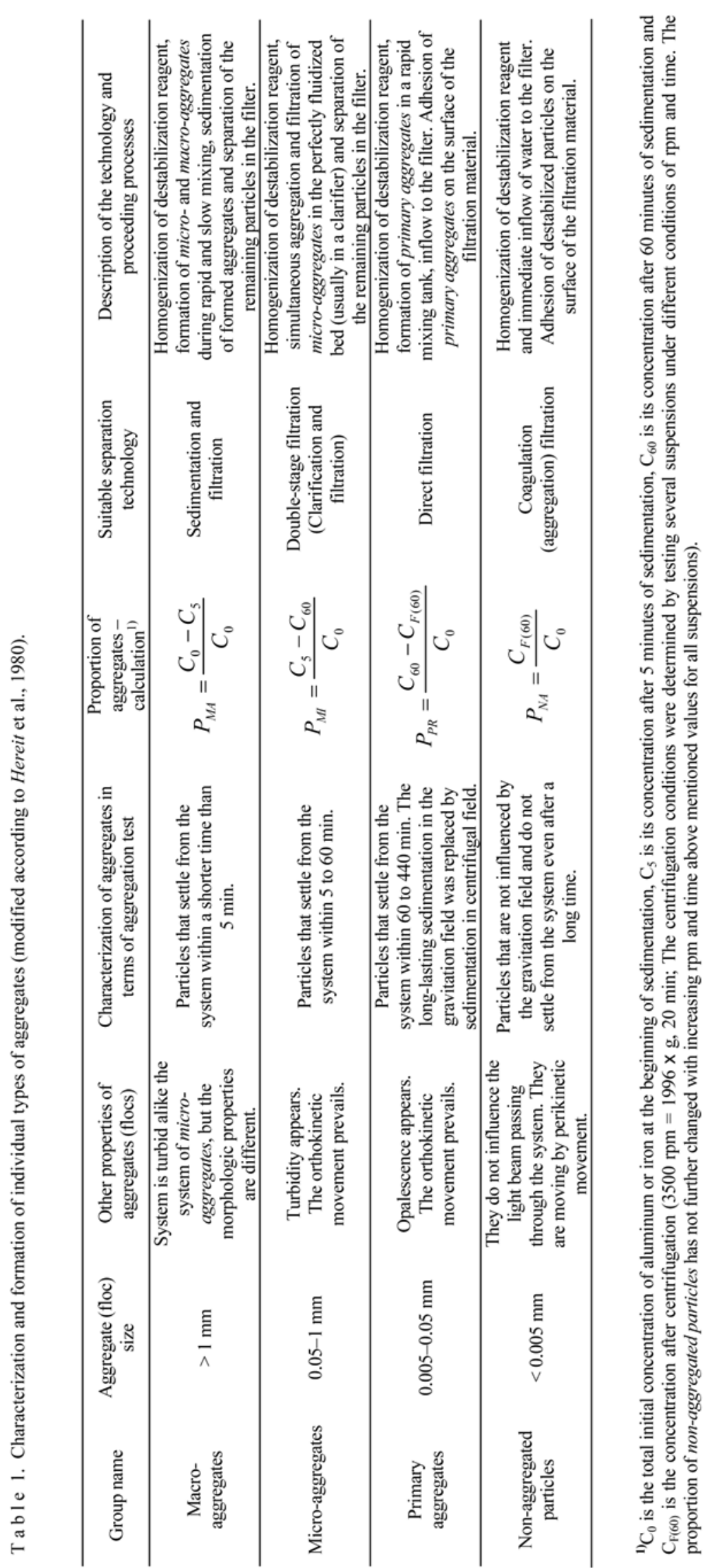


reagent (usually aluminum or iron) is measured in the depth of $40 \mathrm{~mm}$ under the water surface at defined time intervals (at time of zero, five and sixty minutes of sedimentation and after centrifugation see Tab. 1). The volume of $5 \mathrm{ml}$ taken by pipette from the mentioned depth is sufficient for the aluminum/iron analysis. The proportional amount of each group of aggregates can be calculated from the expressions given in Tab. 1.

\subsubsection{Derivation of the aggregation model and test of aggregation}

The method of aggregation test is based on the simple model of aggregation, which assumes several simplified presumptions:

a) The aggregating system contains only one type of particles.

b) The aggregating particles are distributed in the entire volume uniformly.

c) The conditions allowing the movement of the particles are equal for all particles.

d) The growth of aggregates is regular and is done step by step; two neighboring particles are joining to doublets and two neighboring doublets to quadruplets, which are the new units for further aggregation.

e) The basic spherical particles are arranged in the quadruplet in such a way that their centers lie in the tops of the tetrahedron, and the particles touch each other (Fig. 1).

f) The quadruplet is considered as one development population $(P=$ population number $)$.

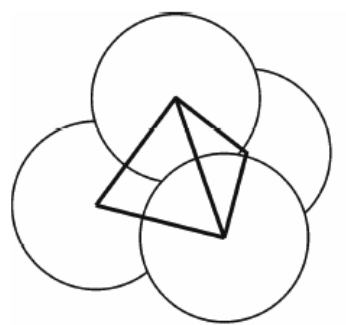

(a)

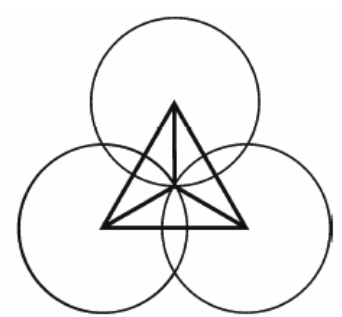

(b)
Fig. 1. a) Schematic illustration of particle arrangement in tetrahedron; b) Top view.

For the calculation, following aggregate properties were defined:

a) The volume of aggregate $V_{P}$ for population $P$ can be calculated as the volume of the sphere circumscribed to the four aggregates of previous population $P-1$, which is limited by four planes touching always three spheres (by tetrahedron circumscribed to these four aggregates). The resulting volume is thus an intersection of these two bodies (Fig. 2):

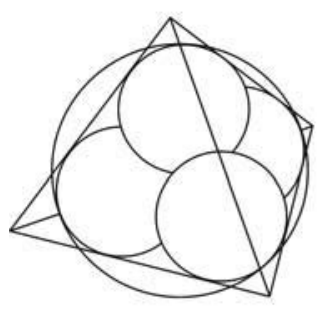

(a)

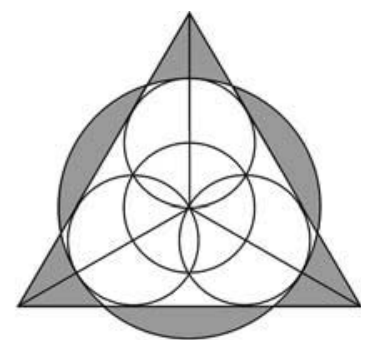

(b)
Fig. 2. a) Schematic illustration of a sphere and tetrahedron circumscribed to four spherical particles of population $P-1 ; \mathrm{b}$ ) Top view: Volume of particle of population $P$ is given by the intersection of a sphere and tetrahedron.

$V_{P}=\pi \frac{53 \sqrt{6}+126}{216} D_{P-1}^{3}=k \cdot D_{P-1}^{3}$,

where $k=3.72$.

b) To the newly formed aggregate of population $P$ and volume $V_{P}$ given by the Eq. (1), an equivalent diameter $D_{P}$ is assigned, which is calculated as the diameter of a sphere of volume $V_{P}$. Together the previous equation holds true, thus:

$V_{P}=\frac{\pi}{6} D_{P}^{3}=k \cdot D_{P-1}^{3}$.

It follows from the previous equation that the diameter of particle of population $P$ is defined as $K$ multiple of the aggregate diameter of the previous population $P-1$ :

$D_{P}=K \cdot D_{P-1}$, where $K=\sqrt[3]{\frac{6 k}{\pi}}=1.92$.

c) Because the real shape of an aggregate is not a sphere, it is needed to adjust the equivalent diameter with a shape factor, which can be expressed as:

$s_{P}=\left(\frac{K^{2}}{4}\right)^{P}$.

d) The porosity of the first population aggregate $\varepsilon_{l}$ is defined as the complement of the ratio of the volume of the four aggregates of the population 0 (four spheres with diameter $D_{0}$ ) to the volume of the population $P_{1}$ (volume of spherical tetrahedron) 


$$
\varepsilon_{1}=1-\frac{4 \cdot V_{0}}{V_{1}}=1-\frac{4 \cdot \frac{\pi}{6} D_{0}^{3}}{k \cdot D_{0}^{3}}=1-\frac{2 \pi}{3 k}=0.4371
$$

The average porosity of an aggregate with population $P$ is then expressed by the relation

$$
\varepsilon_{P}=\varepsilon_{P-1}\left(1-\varepsilon_{1}\right)+\varepsilon_{1}=1-\left(1-\varepsilon_{1}\right)^{P} .
$$

e) The average density of the aggregate $\rho_{P}$ for the purpose of sedimentation velocity calculation is defined as:

$$
\rho_{P}=\rho_{P-1}\left(1-\varepsilon_{1}\right)+\varepsilon_{1} \rho_{f} .
$$

f) The formed aggregate sediments with a velocity $v_{P}$ corresponding to the sedimentation velocity of a sphere with equivalent diameter $D_{P}$ multiplied by the shape factor $s_{P}$.
$v_{P}=\frac{\left(D_{P} s_{P}\right)^{2} g\left(\rho_{P}-\rho_{f}\right)}{18 \eta_{f}}$.

The basic characteristics of different type of particles present in natural water (Tab. 2) were used for the calculation of respective sedimentation velocities $v_{P}$ and other properties. The calculated values for natural particles are given in Tab. 3 .

$\mathrm{T}$ a b 1 e 2. The basic characteristics (diameter and density of particle of population 0) of different type of particles present in natural water according to Hereit et al., 1980.

\begin{tabular}{lcc}
\hline & $D_{0}[\mathrm{~m}]$ & $\rho_{0}\left[\mathrm{~kg} \mathrm{~m}^{-3}\right]$ \\
\hline Humic particles & $2 \cdot 10^{-6}$ & 1200 \\
Clay particles & $1 \cdot 10^{-6}$ & 2500 \\
$\mathrm{Fe}(\mathrm{OH})_{3}$ particles & $5 \cdot 10^{-6}$ & 1500 \\
Natural particles & $1.5 \cdot 10^{-6}$ & 1650 \\
\hline
\end{tabular}

Table 3. Calculated characteristics of natural particles according to the model of aggregation.

\begin{tabular}{cccccc}
\hline$P[-]$ & $D_{P}[\mathrm{~m}]$ & $s_{P}[-]$ & $\rho_{P}\left[\mathrm{~kg} \mathrm{~m}^{-3}\right]$ & $\varepsilon_{P}[-]$ & $v_{P}\left[\mathrm{~cm} \mathrm{~s}^{-1}\right]^{1)}$ \\
\hline 0 & $1.5 \cdot 10^{-6}$ & 1.00 & 1650.0 & 0.000 & $5.414 \cdot 10^{-5}$ \\
1 & $2.880 \cdot 10^{-6}$ & 0.92 & 1365.9 & 0.437 & $9.543 \cdot 10^{-5}$ \\
2 & $5.530 \cdot 10^{-6}$ & 0.85 & 1206.0 & 0.683 & $1.682 \cdot 10^{-4}$ \\
3 & $1.062 \cdot 10^{-5}$ & 0.78 & 1116.0 & 0.822 & $2.965 \cdot 10^{-4}$ \\
4 & $2.038 \cdot 10^{-5}$ & 0.72 & 1065.3 & 0.900 & $5.227 \cdot 10^{-4}$ \\
5 & $3.914 \cdot 10^{-5}$ & 0.66 & 1036.7 & 0.943 & $9.214 \cdot 10^{-4}$ \\
6 & $7.515 \cdot 10^{-5}$ & 0.61 & 1020.7 & 0.968 & $1.624 \cdot 10^{-3}$ \\
7 & $1.443 \cdot 10^{-4}$ & 0.56 & 1011.6 & 0.982 & $2.863 \cdot 10^{-3}$ \\
8 & $2.770 \cdot 10^{-4}$ & 0.52 & 1006.5 & 0.990 & $5.047 \cdot 10^{-3}$ \\
9 & $5.319 \cdot 10^{-4}$ & 0.48 & 1003.7 & 0.994 & $8.897 \cdot 10^{-3}$ \\
\hline 10 & $1.021 \cdot 10^{-3}$ & 0.44 & 1002.0 & 0.997 & $1.568 \cdot 10^{-2}$ \\
\hline 11 & $1.961 \cdot 10^{-3}$ & 0.41 & 1001.1 & 0.998 & $2.765 \cdot 10^{-2}$ \\
12 & $3.764 \cdot 10^{-3}$ & 0.38 & 1000.6 & 0.999 & $4.873 \cdot 10^{-2}$ \\
\hline
\end{tabular}

${ }^{1)}$ The values of $g=9.80665 \mathrm{~m} \mathrm{~s}^{-2}, \rho_{f}=999.97 \mathrm{~kg} \cdot \mathrm{m}^{-3}\left(8^{\circ} \mathrm{C}\right)$ and $\eta_{f}=1.4719 \cdot 10^{-3} \mathrm{~Pa} \cdot \mathrm{s}\left(8^{\circ} \mathrm{C}\right)$ were used for the calculation of sedimentation velocity.

For the purpose of verification of the aggregation model, the sedimentation velocities of aggregates of the diameters $D=0.5,1$ and $2 \mathrm{~mm}$ (approximately corresponding to the diameters of particles with population $P=9,10$ and 11 in Tab. 3) were experimentally measured. Assuming that ten populations are necessary to create the observed aggregate of diameter of $1 \mathrm{~mm}$ (measured sedimentation velocity $\left.=1.55 \cdot 10^{-2} \mathrm{~cm} \cdot \mathrm{s}^{-1}\right)$, the diameter of the basic destabilized particle $(P=0)$ calculated according to the model is equal to $1.47 \cdot 10^{-6} \mathrm{~m}$ and its density to $1670 \mathrm{~kg} \cdot \mathrm{m}^{-3}$, which approximately corresponds to the values given in Tab. 2 .

The sedimentation velocities $v_{P}$ for equivalent diameters $D_{P}$ of each population are plotted on the graph (Fig. 3). The particle diameters of $1 \mathrm{~mm}, 0.05$ $\mathrm{mm}$ and $0.005 \mathrm{~mm}$ were selected as boundary diameters for categorization of aggregates into four mentioned groups according to the requirements of individual separation technologies. The sedimentation velocities for these three diameters were derived from the equation of the line drawn in Fig. 3. Their values are given in Tab. 4 .

The depth of sampling was set at $4 \mathrm{~cm}$ under the water level. The value was chosen to avoid both vertical aggregation and effect of surface tension of water level. The time that a particle of given diameter needs to travel these $4 \mathrm{~cm}$ is calculated in Tab. 4. For the purposes of aggregation test, these values were rounded off. 


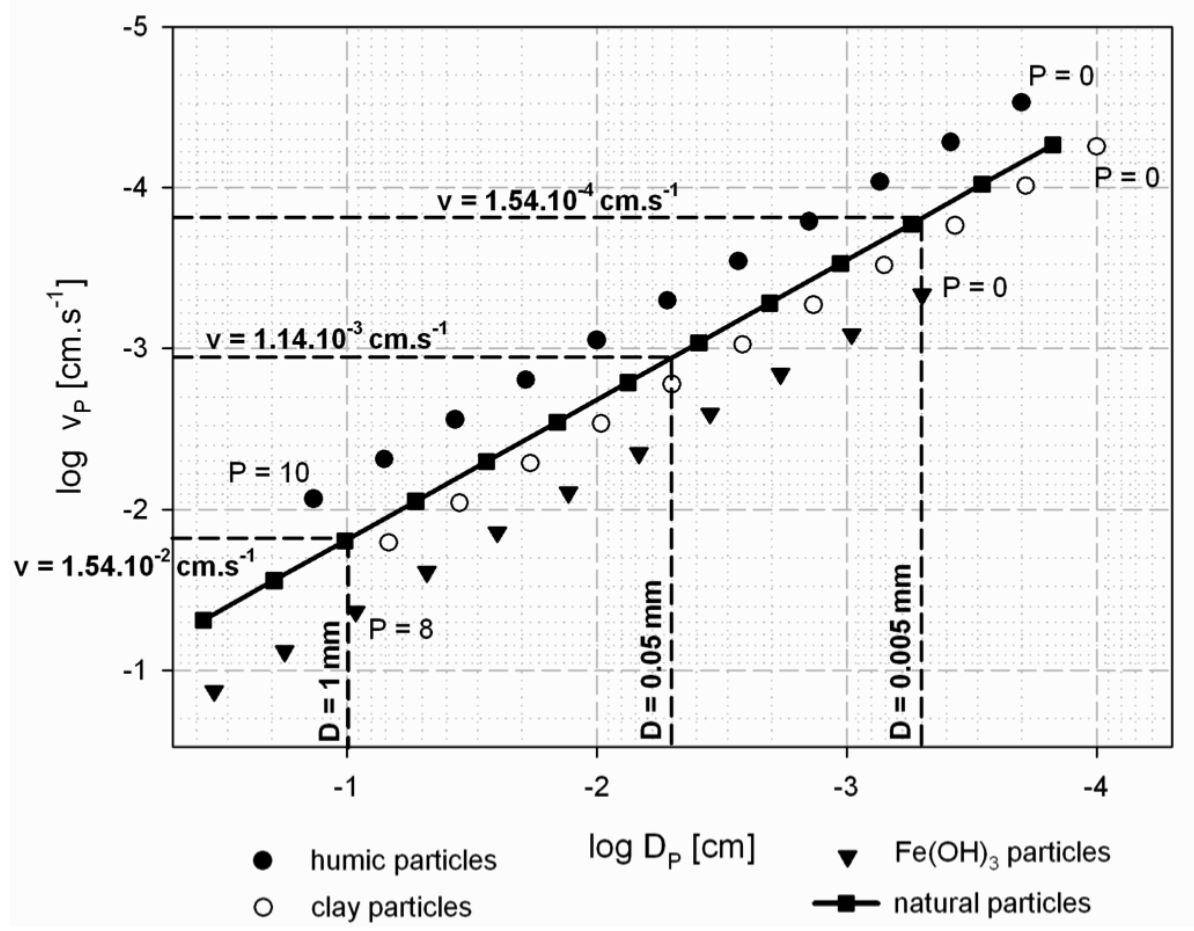

Fig. 3. Dependence of sedimentation velocity of different types of particles on their diameter calculated according to the Eq. (8). The dashed lines represent the boundaries between the four groups of aggregates - MA, MI, PR and NA.

$\mathrm{T}$ a b 1 e 4. Calculated sedimentation velocities for boundary aggregate diameters and time that different types of aggregates need to settle under the chosen distance of $4 \mathrm{~cm}$.

\begin{tabular}{cccc}
\hline$d[\mathrm{~mm}]$ & $v\left[\mathrm{~cm} \mathrm{~s}^{-1}\right]$ & time $[\mathrm{min}]($ for $4 \mathrm{~cm})$ & time [min] (rounded off) \\
\hline $0.005(\mathrm{NA} / \mathrm{PR})$ & $1.54 \cdot 10^{-4}$ & 432.5 & 440 \\
$0.05(\mathrm{PR} / \mathrm{MI})$ & $1.14 \cdot 10^{-3}$ & 58.5 & 60 \\
$1(\mathrm{MI} / \mathrm{MA})$ & $1.54 \cdot 10^{-2}$ & 4.3 & 5 \\
\hline
\end{tabular}

\subsection{Couette reactor - optimization of velocity gradient and retention time}

The effect of the mean velocity gradient $\bar{G}$ and time of its action $t$ on the suspension quality and aggregation efficiency was evaluated using a Couette reactor as a mixing device. It works on the principle of concentric cylinders, the inner one being rotating. The advantage of the Couette reactor lies in a fact that aggregation takes place in a gap between the cylinders, where a uniform distribution of the velocity gradient in a whole mixed volume can be achieved. Paddle stirrers or impellers do not meet this condition. Studies of aggregation under Couette flow have been conducted by several authors (Boadway, 1978; Mutl et al., 2006; Soos et al., 2007).
Raw water (for parameters see Tab. 5) from the reservoir Flaje (Czech Rep.) was used for the research. Aluminum sulfate $\mathrm{Al}_{2}\left(\mathrm{SO}_{4}\right)_{3} \cdot 18 \mathrm{H}_{2} \mathrm{O}$ was used as a destabilization reagent. Raw water was pre-treated using lime water for adjustment of $\mathrm{pH}$ value. Three complete series were measured to ensure good reproducibility.

Dosages of destabilization and alkalization reagent were determined by jar tests at the value of $0.076 \mathrm{mmol} \mathrm{l}^{-1} \mathrm{Ca}(\mathrm{OH})_{2}(\mathrm{pH} \sim 6)$ and $0.023 \mathrm{mmol} \mathrm{l}^{-1}$ $\mathrm{Al}_{2}\left(\mathrm{SO}_{4}\right)_{3} \cdot 18 \mathrm{H}_{2} \mathrm{O}$. The measurements were carried out at a constant temperature of $8.0 \pm 0.5^{\circ} \mathrm{C}$. The values of $\bar{G}=20,40,60,80,100,150,200,250$, 300,350 and $400 \mathrm{~s}^{-1}$ were evaluated. The Reynolds and Taylor numbers for defined velocity gradients are given in Tab. 6. They were calculated from the following equations (9-12). 
T a b l e 5. Quality of raw water from the reservoir Flaje (CZ).

\begin{tabular}{llcc}
\hline Parameter & Min & Max & Average \\
\hline $\mathrm{pH}[-]$ & 6.11 & 6.37 & 6.18 \\
alkalinity $\left[\mathrm{mmol} \mathrm{1}^{-1}\right]$ & 0.12 & 0.20 & 0.18 \\
$\mathrm{COD}_{\mathrm{Mn}}\left[\mathrm{mg} \mathrm{l}^{-1}\right]$ & 5.22 & 6.49 & 5.76 \\
$\mathrm{Al}\left[\mathrm{mg} \mathrm{l}^{-1}\right]$ & 0.04 & 0.28 & 0.12 \\
$\mathrm{DOC}\left[\mathrm{mg} \mathrm{l}^{-1}\right]$ & 6.68 & 7.22 & 7.04 \\
\hline
\end{tabular}

$\mathrm{T}$ a b 1 e 6 . Reynolds and Taylor numbers for real values of velocity gradient.

$$
\begin{aligned}
& \begin{array}{ccc}
\hline \bar{G}\left[\mathrm{~s}^{-1}\right] & \operatorname{Re}[-] & \mathrm{Ta}[-] \\
\hline 20 & 1675 & 562 \\
40 & 3349 & 1123 \\
60 & 5024 & 1835 \\
80 & 6699 & 2446 \\
100 & 8373 & 3058 \\
150 & 12560 & 4586 \\
200 & 16747 & 6005 \\
250 & 20933 & 7644 \\
300 & 25120 & 9173 \\
350 & 29307 & 10701 \\
400 & 33494 & 12230 \\
\hline
\end{array} \\
& U=\omega \cdot \frac{R_{1}+R_{2}}{2}, \\
& T a=\frac{U \cdot d}{v} \cdot \sqrt{\frac{d}{R_{1}}}, \\
& \operatorname{Re}=\frac{U \cdot d}{v} \\
& \bar{G}=2 \pi f\left(\frac{2 R_{1} R_{2}}{R_{2}^{2}-R_{1}^{2}}\right)=\frac{2 \pi r p m}{60}\left(\frac{2 R_{1} R_{2}}{R_{2}^{2}-R_{1}^{2}}\right),
\end{aligned}
$$

where $R_{l}$ is the outer radius of the inner cylinder, $R_{2}$ - the inner radius of the outer cylinder, $d$ - the width of the annular space, $v$ - the kinematic viscosity, $\omega-$ the angular velocity, $U-$ the mean streaming velocity and $f$ is frequency (van Duuren, 1968). It can be seen that the suspension is formed in the region of transitional and turbulent flow.

Individual velocity gradients were applied for $t=$ $=150,300,600,900$ and 1800 seconds $(2.5,5,10$, 15 and $30 \mathrm{~min}$ ). After that tests of aggregation were carried out directly in the Couette reactor and aggregation efficiency of aluminum was evaluated.

\section{Results and discussion}

\subsection{Effect of mixing on suspension quality}

The theory of aggregation test presumes the development (evolution) of aggregates in time according to a scheme (Hereit et al., 1980):

Non-aggregated particles $\rightarrow$ Primary aggregates $\rightarrow$ Micro-aggregates $\rightarrow$ Macro-aggregates

This scheme corresponds to a concept of multilevel structure of flocs, which describes formation of aggregates according to scheme (Gorczyca and Ganczarczyk, 1999; Francois and van Haute, 1985):

Primary particles $\rightarrow$ Flocculi $\rightarrow$ Microflocs $\rightarrow$ Floc aggregates

The process of formation of individual aggregate levels ends on the level given by the velocity gradient used. Low velocity gradients allow the formation of macro-aggregates, while high gradients allow maximally the formation of microaggregates. This statement is also illustrated by the following figures (Figs. 4-7).

In the range of low velocity gradients (20-100 $\mathrm{s}^{-1}$ ), there are all types of aggregates present in the suspension and moreover there is a considerable proportion of non-aggregated particles too (at $\bar{G}=20 \mathrm{~s}^{-1}$, it reaches about $9 \%$ after 30 minutes of mixing). Suspension is then very heterogeneous. Macro-aggregates, suitable for sedimentation, comprise maximally $41 \% \quad\left(\bar{G}=20 \mathrm{~s}^{-1}\right.$, $t=30 \mathrm{~min})$.

On the contrary, at high gradients $\left(150-400 \mathrm{~s}^{-1}\right)$ a suspension consists at the beginning of mixing ( $t=150 \mathrm{~s}$ ) predominantly of primary aggregates (at $\bar{G}=400 \mathrm{~s}^{-1}$ form $95 \%$ of suspension), which turn into micro-aggregates with the mixing time $(t=$ $900 \mathrm{~s})$. Hence the suspension becomes more and more homogeneous with increasing velocity gradient used; the macro-aggregates and non-aggregated proportion decrease almost to the zero value. 


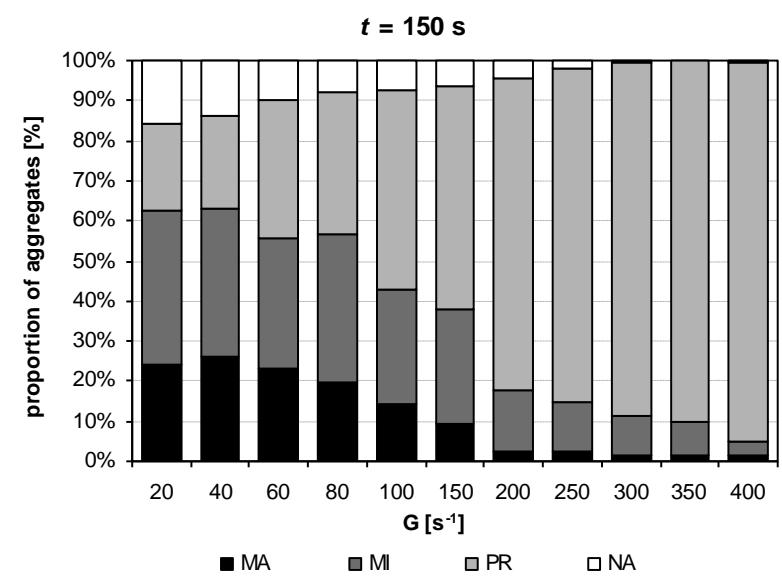

Fig. 4. Proportion of aggregates for different velocity gradients at $t=150 \mathrm{~s}$.

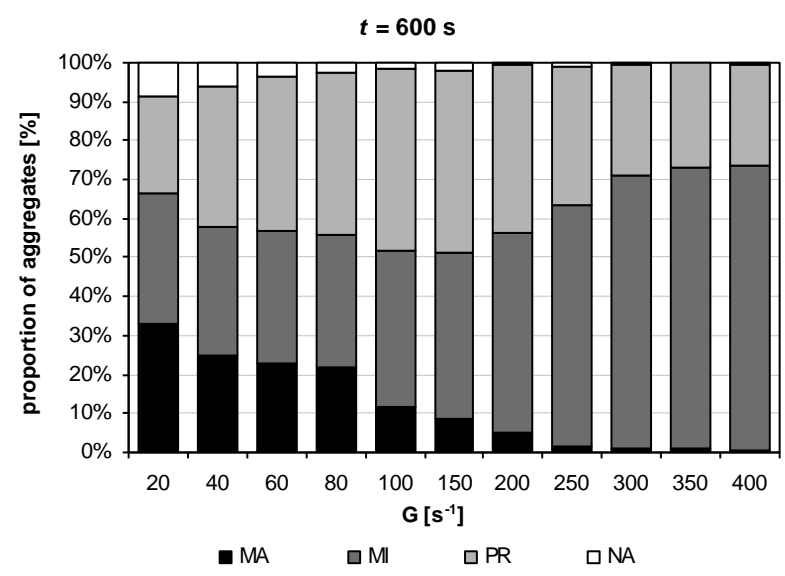

Fig. 6. Proportion of aggregates for different velocity gradients at $t=600 \mathrm{~s}$.

Figs. 8-11 illustrate proportions of individual groups of aggregates in dependence on velocity gradient and mixing time used. These figures confirm that the size of the aggregates decreases with increasing velocity gradient (Bouyer et al., 2005; Hopkins and Ducoste, 2003; Li et al., 2006; Mutl et al., 2006).

Fig. 8 shows that proportion of macroaggregates decreases with increasing $\bar{G}$ and they disappear completely when $\bar{G}>250 \mathrm{~s}^{-1}$. The influence of the mixing time is not very significant especially at higher gradients $\left(\bar{G}>100 \mathrm{~s}^{-1}\right)$.

Unlike macro-aggregates at $\bar{G}<100 \mathrm{~s}^{-1}$ the proportion of micro-aggregates (Fig. 9) is not much influenced by the mixing time and its value ranges between 35 and $45 \%$, while at higher $\bar{G}$ the proportion of micro-aggregates increases with the

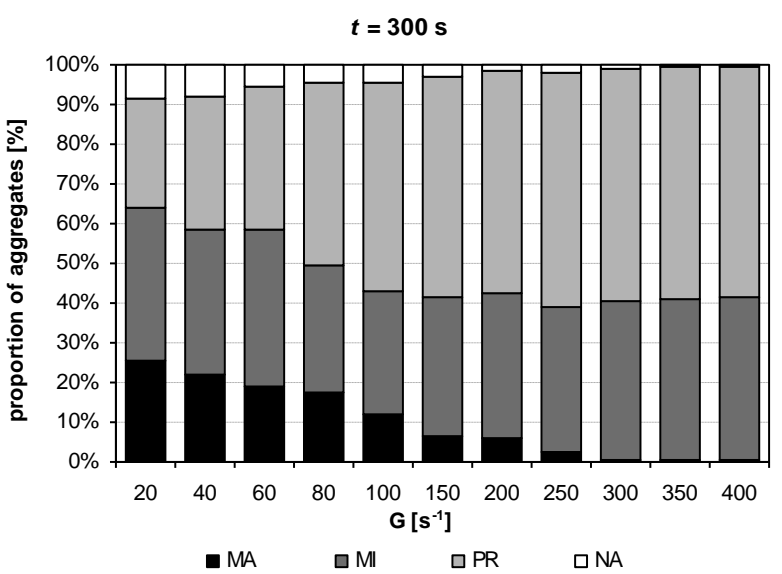

Fig. 5. Proportion of aggregates for different velocity gradients at $t=300 \mathrm{~s}$.

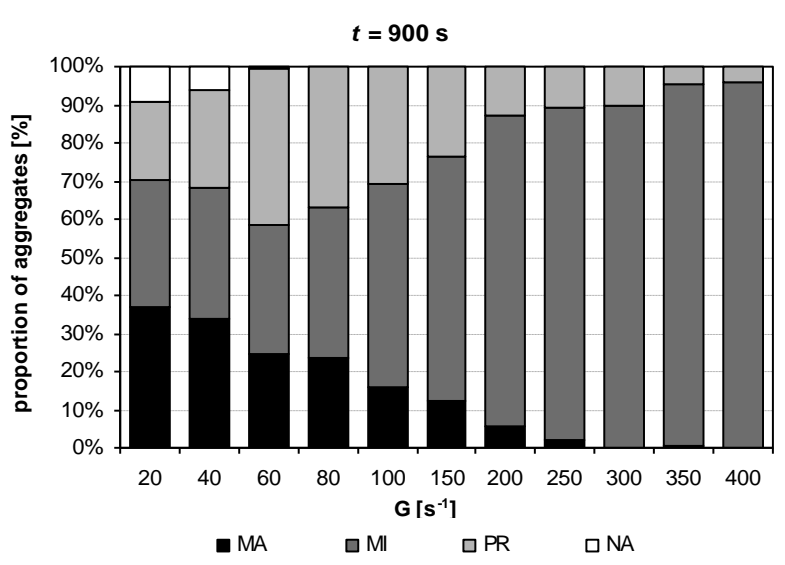

Fig. 7. Proportion of aggregates for different velocity gradients at $t=900 \mathrm{~s}$.

mixing time until reaches the value of approximately $90 \%$ at $t=900 \mathrm{~s}$ and this value does not further change any more.

In the Fig. 10 there is illustrated an inverse trend, when at higher $\bar{G}$ the proportion of primary aggregates decreases with mixing time. It is undoubtedly caused by turning these primary aggregates into micro-aggregates. Again at lower $\bar{G}$ the mixing time does not influence the proportion of primary aggregates, the value of which is around $30 \%$.

Non-aggregated particles are undesirable from technological point of view and it is important to notice that at $\bar{G}=20$ and $40 \mathrm{~s}^{-1}$ the non-aggregated particles does not decrease but remain at a value around $8 \%$ (Fig. 11). On the contrary, at $\bar{G} \geq 100 \mathrm{~s}^{-1}$ after 15 minutes it practically approaches zero. 


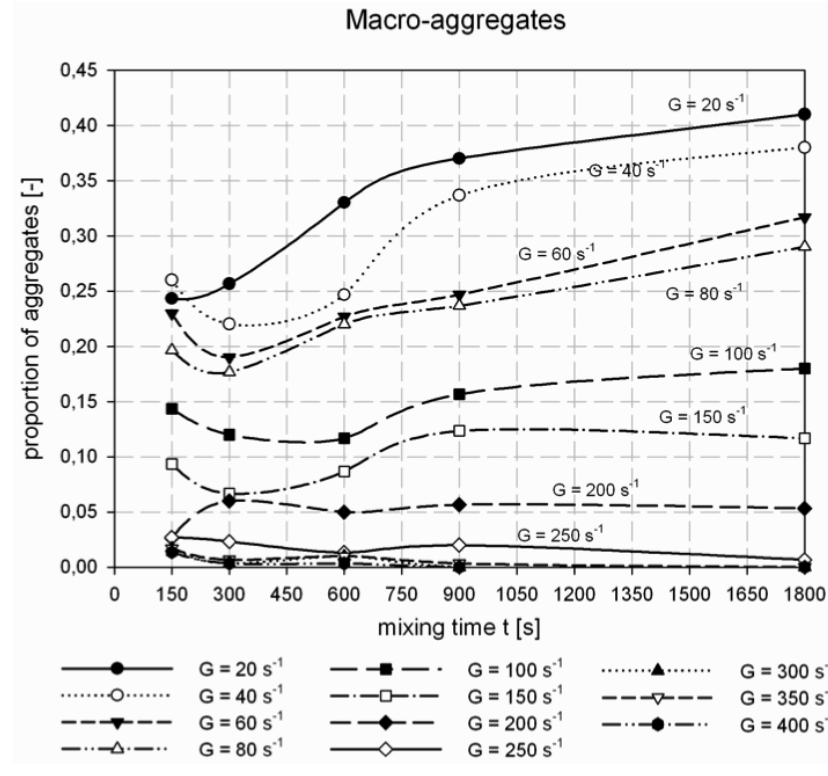

Fig. 8. Proportion of macro-aggregates at given mixing time for different velocity gradients.

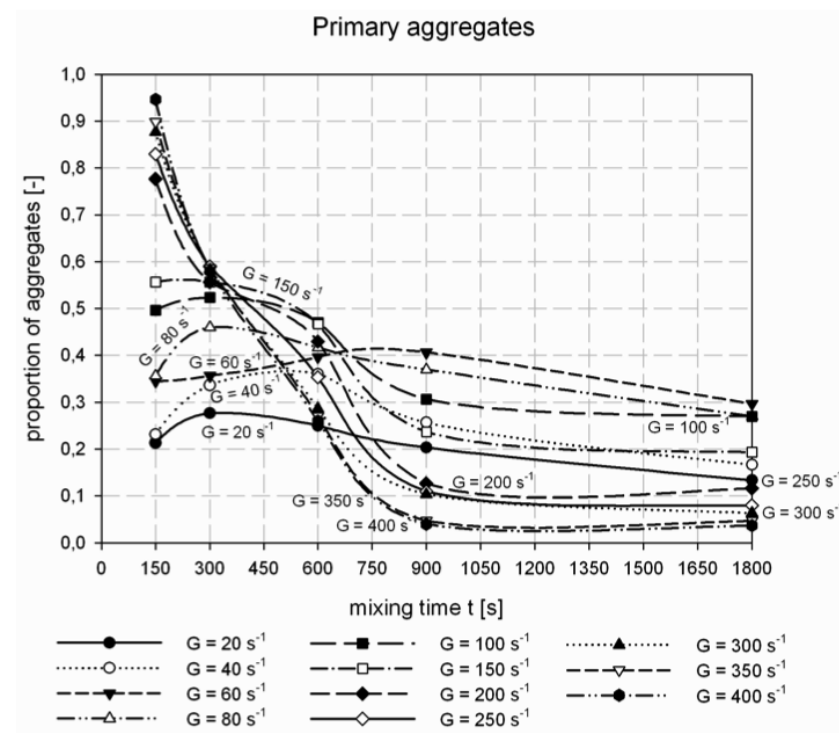

Fig. 10. Proportion of primary aggregates at given mixing time for different velocity gradients.

Generally it can be stated that at low gradients $\bar{G}=20-80 \mathrm{~s}^{-1}$ ) the destabilized particles gradually transform across all levels to micro- and macroaggregates, but certain proportion of nonaggregated particles remains. In the range of middle gradients $\left(\bar{G}=100-250 \mathrm{~s}^{-1}\right)$ a continual trend of decrease of primary aggregates, which turn to micro-aggregates and partly to macro-aggregates, can be observed. When high gradients $(\bar{G}=300-$

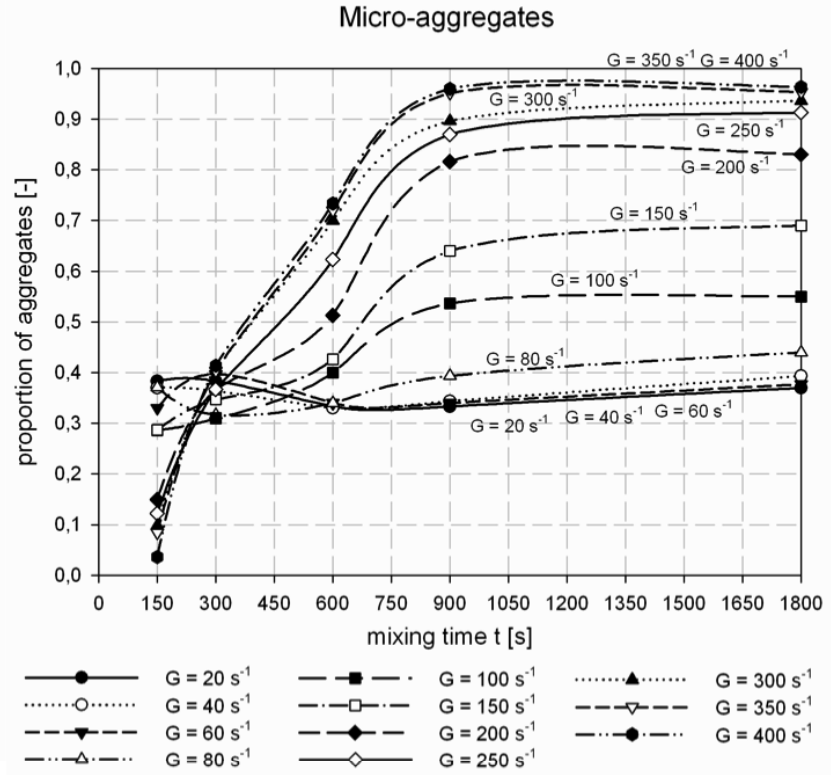

Fig. 9. Proportion of micro-aggregates at given mixing time for different velocity gradients.

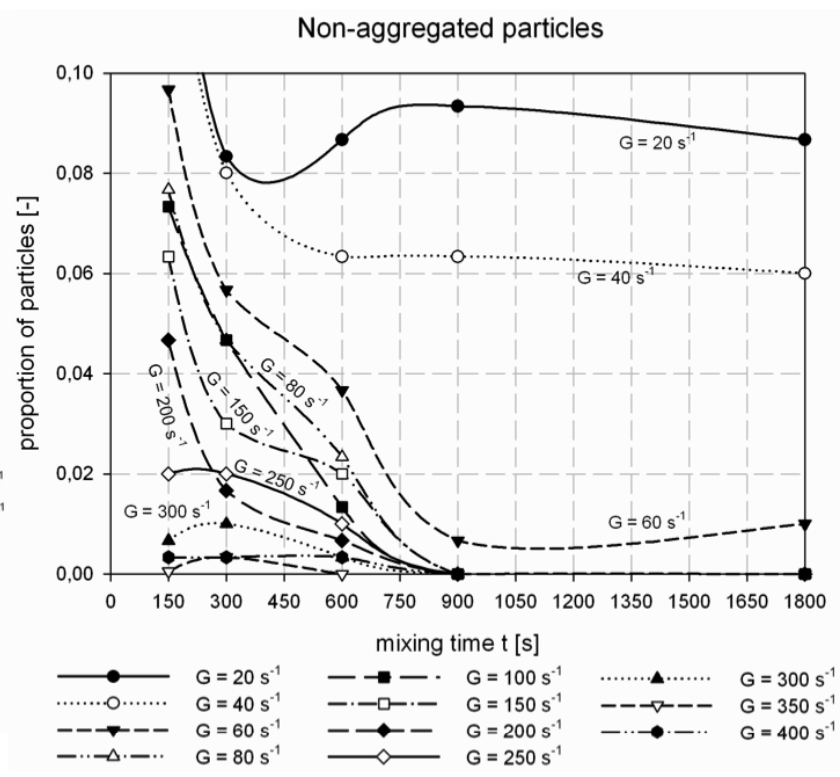

Fig. 11. Proportion of non-aggregated particles at given mixing time for different velocity gradients.

$-400 \mathrm{~s}^{-1}$ ) are applied, the zero values of macroaggregates and non-aggregated particles are reached yet after $150 \mathrm{~s}$ of mixing. The fundamental feature is then a gradual transformation of primary aggregates to micro-aggregates, which become to predominate in the system after $t=300 \mathrm{~s}$.

It follows from the achieved results that the intensity and time of mixing essentially influence the properties of formed suspension. It is undisputed that chemical composition and character of mole- 
cules present in raw water, type and dosage of destabilization reagent used and reaction $\mathrm{pH}$ influence the suspension properties as well (Annadurai et al., 2004; Polasek and Mutl, 2005), but their effect asserts itself more during destabilization. If a maximal possible destabilization under defined conditions is achieved, the decisive presumption for reaching high-quality drinking water is a high efficiency of aggregation, which essentially influences the efficiency of following separation steps (Hereit et al., 1980; Mutl et al., 2006). It is needed to choose the optimal magnitude of the mean velocity gradients and mixing time with respect to input quality of raw water, the destabilization reagent used and expected way of suspension separation. It is really astounding that while the destabilization conditions (reagent and $\mathrm{pH}$ ) are commonly optimized in practice, the conditions of aggregation (mixing) are often neglected.

\subsection{Statistical evaluation of aggregation test}

The reproducibility of the method of aggregation test was evaluated using a method of Analysis of Variance (ANOVA) - the two way design with replication. The tests were performed by three different appraisers in two series of five samples under the identical conditions of $\bar{G}=150 \mathrm{~s}^{-1}$ and $t=900 \mathrm{~s}$. The proportions of all groups of aggregates were calculated. Each group was evaluated with ANOVA separately. The proportion of macro-aggregates is used for the illustration of the calculation. The basic data used for ANOVA are given in Tab. 7.

T a b 1 e 7. Data for the ANOVA analysis: Proportion of macro-aggregates measured by three different people under conditions of $\bar{G}=150 \mathrm{~s}^{-1}$ and $t=900 \mathrm{~s}$.

\begin{tabular}{lrr}
\hline & 1 & 2 \\
\hline Appraiser 1 & 0.12 & 0.13 \\
& 0.12 & 0.12 \\
& 0.11 & 0.12 \\
& 0.12 & 0.10 \\
& 0.10 & 0.11 \\
\hline Appraiser 2 & 0.11 & 0.12 \\
\hline & 0.13 & 0.11 \\
& 0.12 & 0.12 \\
& 0.12 & 0.10 \\
Appraiser 3 & 0.11 & 0.13 \\
\hline & 0.11 & 0.12 \\
\hline & 0.10 & 0.11 \\
& 0.12 & 0.11 \\
& 0.12 & 0.10 \\
\hline & 0.11 & 0.11 \\
\hline
\end{tabular}

The ANOVA method was performed with use of Statistica 7.1 (StatSoft, Inc.). The results are summarized in Tab. 8. The null hypotheses were tested at the significance level of $\alpha=0.05$. They were accepted for all groups of aggregates (in all cases, $F_{\text {crit }}>F$ and $P>\alpha$.). It means that no significant deviation between different appraisers or different series was found and there is no interaction between these two factors.

\section{Conclusions}

Based on the previous findings, it can be summarized that:

- The method of the aggregation test is a simple, inexpensive method of evaluating suspension quality, which can be used both in laboratory and operation conditions. It categorizes the aggregates formed during mixing into four groups (macro-aggregates, micro-aggregates, primary aggregates and non-aggregated particles) on the basis of their diameters and sedimentation velocities. The test of aggregation does not require any special skills or understanding of complicated techniques. The basic knowledge of laboratory technician is sufficient. It provides a satisfactory reliability for evaluation of suspension quality for purposes of waterworks operation.

- The applied mean velocity gradient influences the size and size distribution of formed aggregates and also its changes with time. When a higher gradient is applied $\left(\bar{G}>100 \mathrm{~s}^{-1}\right)$, suspensions with homogeneous representation of aggregates, where micro-aggregates predominate, are formed (which is favourable to single-stage separation by filtration). When a lower gradient is used $\left(\bar{G}<100 \mathrm{~s}^{-1}\right)$, the size distribution of aggregates in suspension is of a relatively wide range; there are both large aggregates (macroaggregates) and the smaller ones (primary aggregates and micro-aggregates) in the system and the suspension is substantially more heterogeneous.

- The proportion of individual groups of aggregates is also dependent on the mixing time. After a mixing time specific for given velocity gradient, the size of aggregates reaches the steady state, after which it does not change any further. This time needed for reaching a steady-state size of aggregates becomes shorter with increasing value of velocity gradient. 
T a b le 8. Two-way ANOVA with replication.

\begin{tabular}{|c|c|c|c|c|c|c|}
\hline & & & 1 & 2 & & Total \\
\hline \multirow{4}{*}{ Appraiser 1} & Count & & 5 & 5 & & 10 \\
\hline & Sum & & 0.57 & 0.58 & & 1.15 \\
\hline & Average & & 0.114 & 0.116 & & 0.115 \\
\hline & Variance & & $8 \cdot 10^{-5}$ & $1.3 \cdot 10^{-4}$ & & $9.44 \cdot 10^{-5}$ \\
\hline \multirow{4}{*}{ Appraiser 2} & Count & & 5 & 5 & & 10 \\
\hline & Sum & & 0.59 & 0.58 & & 1.17 \\
\hline & Average & & 0.118 & 0.116 & & 0.117 \\
\hline & Variance & & $7 \cdot 10^{-5}$ & $1.3 \cdot 10^{-4}$ & & $9 \cdot 10^{-5}$ \\
\hline \multirow{4}{*}{ Appraiser 3} & Count & & 5 & 5 & & 10 \\
\hline & Sum & & 0.56 & 0.55 & & 1.11 \\
\hline & Average & & 0.112 & 0.11 & & 0.111 \\
\hline & Variance & & $7 \cdot 10^{-5}$ & $5 \cdot 10^{-5}$ & & $5.44 \cdot 10^{-5}$ \\
\hline \multirow{4}{*}{ Total } & Count & & 15 & 15 & & \\
\hline & Sum & & 1.72 & 1.71 & & \\
\hline & Average & & 0.11467 & 0.114 & & \\
\hline & Variance & & $6.95 \cdot 10^{-5}$ & $9.71 \cdot 10^{-5}$ & & \\
\hline \multicolumn{7}{|l|}{ ANOVA } \\
\hline Source of variation & $S S$ & $d f$ & $M S$ & $F$ & $P$-value & $F$ crit. \\
\hline Sample & $1.87 \cdot 10^{-4}$ & 2 & $9.33 \cdot 10^{-5}$ & 1.0566 & 0.3633 & 3.4028 \\
\hline Column & $3.33 \cdot 10^{-6}$ & 1 & $3.33 \cdot 10^{-6}$ & 0.0377 & 0.8476 & 4.2597 \\
\hline Interaction & $2.67 \cdot 10^{-5}$ & 2 & $1.33 \cdot 10^{-5}$ & 0.1509 & 0.8607 & 3.4028 \\
\hline Within & 0.00212 & 24 & $8.83 \cdot 10^{-5}$ & & & \\
\hline Total & 0.002337 & 29 & & & & \\
\hline
\end{tabular}

Acknowledgement. The research project has been funded by the Czech Science Foundation under the project No. P105/11/0247 and Institutional Research Plan No. AV0Z20600510. The authors acknowledge the financial assistance on this project.

\section{REFERENCES}

ANNADURAI G., SUNG S.S., LEE D.J., 2004: Optimization of floc characteristics for treatment of highly turbid water. Sep. Sci. Technol., 39, 1, 19-42.

BOADWAY J.D., 1978: Dynamic of growth and breakage of alum floc in presence of fluid shear. Proc. ASCE, J. Envir. Engng. Div., EE5, 104, 901-915.

BOUYER D., COUFORT C., LINE A., DO-QUANG Z., 2005: Experimental analysis of floc size distributions in a 1-L jar under different hydrodynamics and physicochemical conditions. J. Colloid Interface Sci., 292, 2, 413-428.

CHAKRABORTI R.K., GARDNER K.H., KAUR J., ATKINSON J.F., 2007: In situ analysis of flocs. J. Water Suppl. Res. \& Technol. - AQUA, 56, 1, 1-11.

CHENG W.P., KAO Y.P., YU R.F., 2008: A novel method for on-line evaluation of floc size in coagulation process. Wat. Res., 42, 10-11, 2691-2697.

DROPPO I.G., KRISHNAPPAN B.G., JASKOT C., 2006 Evaluation of a laser-assisted particle sizing/settling velocity determination technique. Hydrol. Process., 20, 9, 1885-1893.

VAN DUUREN F.A., 1968: Defined velocity gradient model flocculator. Proc. Am. Soc. Civ. Engrs., J. San. Eng. Div., SA4, 671-682.
FARGUES C., TURCHIULI C., 2003: Structural characterization of flocs in relation to their settling performances. Chem. Eng. Res. \& Design, 81, A9, 1171-1178.

FRANCOIS R.J., VAN HAUTE A.A., 1985: Structure of hydroxide flocs. Water Res., 19, 10, 1249-1254.

GORCZYCA B., GANCZARCZYK J., 1999: Structure and porosity of alum coagulation flocs. Water Qual. Res. J. Can., 34, 4, 653-666.

GREGORY J., 2009: Monitoring particle aggregation processes. Adv. Colloid Interface Sci., 147-48, 109-123.

HEREIT F., MUTL S., VAGNER V., 1980: The formation of separable suspensions and the methods of its assessment. AQUA, 5, 95-99.

HOPKINS D.C., DUCOSTE J.J., 2003: Characterizing flocculation under heterogeneous turbulence. J. Colloid Interface Sci., 264, 1, 184-194.

KILANDER J., BLOMSTROM S., RASMUSON A., 2006: Spatial and temporal evolution of floc size distribution in a stirred square tank investigated using PIV and image analysis. Chem. Eng. Sci., 61, 23, 7651-7667.

LI T., ZHU Z., WANG D.S., et al., 2006: Characterization of floc size, strength and structure under various coagulation mechanisms. Powder Technol., 168, 2, 104-110.

MUTL S., POLASEK P., PIVOKONSKY M., KLOUCEK O., 2006: The influence of $G$ and $T$ on the course of aggregation in treatment of medium polluted surface water. Water Sci. \& Technol.: Water Suppl., 6, 1, 39-48.

PIVOKONSKY M., PIVOKONSKA L., TOMASKOVA H., 2008: Aggregation capability of a fluidised layer of granular material during treatment of water with high DOC and low alkalinity. Water Sci. \& Technol.: Water Suppl., 8, 1, 9-17.

PIVOKONSKY M., PIVOKONSKY R., BENESOVA L., MUTL S., 2003: Methodology of evaluation of size and 
size-distribution of particles formed during aggregation. J. Hydrol. Hydromech., 51, 4, 281-287.

PIVOKONSKY M., POLASEK P., PIVOKONSKA L., TOMASKOVA H., 2009: Optimized reaction conditions for removal of Cellular Organic Matter of Microcystis aeruginosa during the destabilization and aggregation process using ferric sulfate in water purification. Water Env. Res., $81,5,514-522$.

POLASEK P., MUTL S., 2005: Optimisation of reaction conditions of particle aggregation in water purification - back to basics. Water SA, 31, 1, 61-72.
SOOS M., WANG L., FOX R.O., SEFCIK J., MORBIDELLI M., 2007: Population balance modeling of aggregation and breakage in turbulent Taylor-Couette flow. J. Colloid Interface Sci., 307, 433-446.

TAMBO N., WATANABE Y., 1979: Physical characteristics of flocs - I. The floc density function and aluminium floc. Water Res., 13, 5, 409-419.

Received 26 April 2010 Accepted 12 April 2011 